\title{
Start and spread of forest fire: A Case Study in the Federal Conservation Unit Serra de Santa Barbara, Mato Grosso state, Brazil
}

\author{
Ian Felipe Cabral ${ }^{l},{ }^{3}$ *, Luciana Sanches ${ }^{l}$, Vanusa de Souza Pacheco Hoki ${ }^{l},{ }^{2}$, Camylla Kerly Pereira \\ Mariano $^{1}$, Marco Aurelio Aires da Silva ${ }^{3}$
}

\footnotetext{
${ }^{1}$ University of Mato Grosso (UFMT), Cuiabá, Mato Grosso, Brazil

${ }^{2}$ University of Cuiabá (UNIC), Cuiabá, Mato Grosso, Brazil

${ }^{3}$ Environmental Emergency Catalog (BEA), Cuiabá, Mato Grosso, Brazil

*Contact email: agro.ifc@gmail.com, lsanches@ hotmail.com, vanusahoki@gmail.com, camylla_kerly@hotmail.com, s1airessbm@ hotmail.com
}

\begin{abstract}
Spatial patterns of start of forest fires define the structure of the spatial pattern of fires which may have different sizes and levels of severity generating a mosaic of burned areas. The aim of our study was to analyze the Serra de Santa Barbara a Federal Conservation Unit composed of transition areas between the Amazonia, Cerrado and Pantanal biomes with an area of 120,092 hectares, located in Pontes and Lacerda and Porto Esperidião municipalities in Mato Grosso state, Brazil. In 2018, the Federal unit had seven days of burningresulting in $8 \%$ of the Conservation unit burned. In this context, the start and spread of forest fire were analyzed using data from burn outbreaks (obtained from the Instituto Nacional de Pesquisas Espaciais (INPE); boundaries of protected areas Instituto Chico Mendes (CMBio); description of protected areas in the Conservation Units Register (obtained by CNUC - MMA); responsible for the State Conservation Units (obtained by SEMA / MT) and LandSat 8 satellite images (obtained by the OLI sensor, composition RGB654). By analyzing the data, We found that the start of the fire was around 9:03 am (07/22/2018) spreading on the main front as an elongated elliptical shape, characteristic of flat terrain with wind. The fire finished at 20h03min (24/07/2018) with a distance of $1 \mathrm{~km}$ from the left flank to the right. Our results indicated that the fire burned the humid vegetation, with low air temperature and high relative humidity. Most of the fire propagation was nocturnal and when the fire spread it converged due to the uphill formations and to the solar radiation effects at sunrise together with the atmospheric convection process caused by thermal inversion. Understanding the start and spread of forest fire allows us to evaluate evidences of fire points and in the adjacent areas allowing a better assessment of the causes of the fire start.
\end{abstract}

Keywords: transition area, fire ignition, night fire, forest fire, topography. 